\title{
Exploring Techniques of Developing Writing Skill in IELTS Preparatory Courses: A Data-Driven Study
}

\author{
Seyyed Ali Ostovar-Namaghi ${ }^{1} \&$ Seyyed Esmail Safaee ${ }^{1}$ \\ ${ }^{1}$ Department of Applied Linguistics, Shahrood University of Technology, Iran \\ Correspondence: Seyyed Ali Ostovar-Namaghi, Department of Applied Linguistics, Shahrood University of \\ Technology, Iran. E-mail: saostovarnamaghi@yahoo.com
}

Received: October 3, 2016

Accepted: February 4, 2017 Online Published: February 6, 2017

doi: 10.5539/elt.v10n3p74

URL: http://doi.org/10.5539/elt.v10n3p74

\begin{abstract}
Being driven by the hypothetico-deductive mode of inquiry, previous studies have tested the effect of theory-driven interventions under controlled experimental conditions to come up with universally applicable generalizations on teaching writing. To make a case in the opposite direction, this data-driven study aims at uncovering techniques and strategies experienced teachers use in developing IELTS candidates' writing skill rather than testing the effect of externally imposed interventions. Following the constructivist grounded theory procedures, participants' perspectives on techniques of teaching writing in IELTS preparatory courses were theoretically sampled through open-ended interviews. Iterative data collection and analysis revealed techniques such as exposing candidates to sample answers, teaching grammar and vocabulary as a prerequisite to writing, teaching prefabricated patterns, raising candidates' awareness of scoring criteria, teaching discourse markers, and encouraging learners to develop their content knowledge. The findings have clear implications for both test takers who look for effective techniques of developing their writing skills and practitioners who strive to develop candidates' writing skills in IELTS preparatory courses.
\end{abstract}

Keywords: IELTS preparatory courses, writing skill, teaching strategies, teachers' perspectives

\section{Introduction}

Being practitioners ourselves, we read the latest theoretical perspectives and empirical findings to develop our teaching skills in running IELTS preparatory courses. Very few of the previous studies, however, proved useful since the findings of these studies which aimed at testing theory-driven interventions were inconclusive and incomprehensible. They were inconclusive in that they presented the reader with contradictory findings and they were incomprehensible because they presented their findings in terms of complicated equations and technical jargons which made them difficult to follow because they are meaningless to the average practitioner. Moreover, being driven by the experimental mode of research, none of the previous studies explored seasoned practitioners' perspectives on teaching writing to IELTS candidates.

To fill in this gap, this study aims at uncovering the techniques and strategies implicit in the practice of experienced EFL teachers by theoretically sampling their perspectives and abstracting and conceptualizing them through the coding schemes of grounded theory. The findings of the study are significant in that they add to the body of knowledge on teaching writing since they theorize practitioners' perspectives which complement the findings of theory-driven studies. They are equally significant in that not only do they provide practitioners teaching writing to IELTS candidates with down-to-earth techniques and strategies, they also provide IELTS candidates with clear guidelines and strategies on how to develop their writing skill and improve their band score in IELTS.

\section{Review of Previous Empirical Findings}

Some studies have explored the effect of task type on IELTS candidates' writing performance (e.g., Ahmadi \& Mansoordehghan, 2014; Lan, 2015; O'Loughlin \& Wigglesworth, 2003). To start with, Ahmadi and Mansoordehghan (2014) compared the effect of task 1 and task 2 of IELTS writing module on test-takers' writing performance and found that there is no significant difference between the performance of test takers in these tasks. On the other hand, Lan (2015) found that when the test requires a low-demanding task such as task 1, i.e., graphic description, test takers perform significantly better in terms of accuracy. On the other hand, a 
high-demanding task yields more complex texts with lexical variations and grammatical subordinations. Similarly, O'Loughlin and Wigglesworth (2003) found that simpler tasks, which require less information to be processed, elicit more complex structures.

On the other hand, some studies have tested the effect of instructional interventions such as exposing candidates to sample essays (e.g., Ambe, 2008; Bagheri \& Zare, 2009). For instance, Bagheri and Zare (2009) found that exposing candidates to model essays improves their awareness of writing features such as form, discourse, relevancy, and lexical resources. Similarly, Ambe (2008) found that Japanese ESL learners improved their writing skill by comparing their essays with model essays and noticing the gap between their essays and the model essays in terms of lexis, form, discourse, and content. He also found that the degree of noticing is contingent upon language learners' proficiency and task types.

Focusing on effective interventions, other studies have explored candidates' samples essays in terms of the appropriate use of discourse markers (e.g., Ahmadi-Fatalaki \& Nazari, 2015; Serajfard \& Allami, 2012; Patriana, Rachmajanti \& Mukminatien, 2016). For example, Ahmadi-Fatalaki and Nazari (2015) found that most of the IELTS candidates used boosters and framework meta-discourse markers as the most-frequently used techniques to improve the quality of their writings. Similarly, Patriana, Rachmajanti, and Mukminatien (2016) found that although EFL learners use discourse markers to write coherent texts, they do not use them appropriately. As a complementary study, Serajfard and Allami (2012) found that teaching engagement markers resulted in more effective writings by IELTS students.

As another effective intervention, some studies have explored the effect of involving candidates in collaborative writing (e.g., Ajideh, Leitner, \& Yazdi-Amirkhiz, 2016; Elola \& Oskoz, 2010; Sanonguthai, 2011; Storch, 2005). For example, Ajideh, Leitner, and Yazdi-Amirkhiz (2016) found that collaborative writing improves students' writing only in terms of task achievement and cohesion and coherence. Likewise, Sanonguthai (2011) found that involving learners in collaborative brainstorming and debating of the topic prior to writing significantly improves candidates' writing skills. In another similar study, Storch (2005) compared the differences between texts written by individual learners and those produced by pairs and found that while individuals produced longer texts, pairs composed richer texts with regard to complexity of the text, task fulfillment, and grammatical accuracy. In drastic contrast with (Storch, 2005), Elola and Oskoz (2010) found that there is no significant difference between learners' writing when they wrote individually and collaboratively.

Rather than exploring methods and materials of teaching writing, some studies have explored the use of technology in helping candidates overcome their writing difficulties and improve their writing skills (e.g., Abuseileek, 2006; Armstrong \& Retterer, 2008; Van-Leeuwen \& Gabriel, 2007; Lin, Groom, \& Lin, 2013; Ocriciano, 2016; Vurdien, 2012). As a clear example, Ocriciano (2016) found that gamification motivates students and improves their IELTS writing skills in terms of spelling, vocabulary. In a similar study, Leeuwen and Gabriel (2007) found that word processors significantly improve IELTS candidates' spelling since they enables candidates to recognize their spelling errors and presents them with accurate spelling. Similarly, Abuseileek (2006) found that practicing writing through word processors is more beneficial than the pen and paper practice of writing. In a similar study, Lin, Groom, and Lin (2013) explored candidates' perceptions of blogs and found that candidates have a positive perception of blogs since they believed that blogs help them to learn and remember what they need to use in their writing.

As another line of research, some studies explored the effect of corrective feedback on candidates' writing performance in IELTS (e.g., Ganji, 2009; Ketabi \& Torabi, 2013; Paulus, 1999; Vahdani-Sanavi \& Nemati, 2014). As a prime example, Ganji (2009) discovered that IELTS candidates who were treated by peer-correction and self-correction outperformed those who were treated by traditional teacher correction. Moreover, they found that peer-correction was the most effective technique of providing learners with corrective feedback. Similarly, Ketabi and Torabi (2013) found that peer correction is more effective than teacher correction in teaching writing skills. In a similar study, Vahdani-Sanavi and Nemati (2014) found that applying corrective strategies including direct form, indirect form, error coding, peer correction, meta-linguistic feedback significantly improved learners' performance in writing task 2 .

\section{Purpose of the Study}

As the review of related empirical findings clearly shows, previous studies have focused on testing the effect of materials and methods on IELTS candidates' performance in writing tasks; hence, except for one or two studies which were descriptive, a great majority of the previous empirical studies were experimental in nature. Despite the importance of IELTS teachers' perceptions and practices, however, none of the reviewed studies, explored teachers' perspectives on teaching writing to IELTS candidates. To fill in this gap, this study aims at uncovering 
the techniques seasoned EFL teachers' use in teaching writing to IELTS candidates by exploring their perspectives through open-ended qualitative interviews.

\section{Research Design}

To ensure a solid research design, the researcher should choose a research method which is congruent with his or her beliefs about the nature of reality. We believe that the researcher and the participants co-construct meaning in the interactive process of data collection. More specifically, in line with constructivist grounded theory, we believe that "data do not provide a window on reality. Rather, the 'discovered' reality arises from the interactive process and its temporal, cultural, and structural contexts" (Charmaz, 2000, p. 524); therefore, the constructivist design is based on the assumption that the interaction between the researcher and the participants produces the data and the meanings attached to them in the interactive process of data collection and analysis.

\subsection{Sampling Procedure and Participants}

Instead of using the statistical sampling procedure, which is common in hypothetico-deductive mode of inquiry, this study made use of purposive, snowball and theoretical sampling procedures respectively. Initially, based on word-of-mouth communication, we selected a very popular language teacher running IELTS preparatory courses. Having interviewed him, we asked the participant to introduce other qualified and interested participants. In other words, following snowball sampling, one participant recruited other interested participants (Hancock, Windridge, \& Ockleford, 2007). Finally, in line with grounded theory, we theoretically sampled their perspectives to uncover the strategies and techniques experienced teachers use in developing EFL learners' writing skill in IELTS preparatory course. Having interviewed thirteen participants, the emerged techniques and strategies reached a point of theoretical saturation.

\subsection{Data Collection and Analysis}

Following Charmaz (2006), we collected the participants' perspectives on developing EFL learners' writing skill in IELTS preparatory coursed through what is known as intensive interviewing. The interviews were designed to acquaint the participant with the nature of the study, to establish rapport, to set a context, and then to obtain depth and details of IELTS teachers' experience (Ostovar-Namaghi, 2009). Along these lines, the study started with the grand tour question, "What strategies and techniques do you use in developing EFL learners' writing skill in IELTS preparatory courses you run?" Initial data collection and analysis aimed at uncovering the techniques. Subsequent iterative data collection and analysis, however, aimed at uncovering participants' elaboration, clarification, and exemplification of the emerged techniques. Interviewing, memoing and coding continued until the emerged techniques reached a point of theoretical saturation.

To uncover and clarify techniques of developing writing skills in IELTS preparatory courses, we interviewed the participants and having had their informed consent, audio-taped their perspectives followed by a verbatim transcription of the data. Applying the coding schemes of grounded theory including open coding, axial coding and selective coding enabled us to sift through the data, abstract them, and come up with a set of themes indicating the strategies and techniques participants used in developing IELTS' candidates writing skill.

\subsection{Ethical Issues and Trustworthiness}

To address the ethical issues, we followed a multi-pronged approach. First, in line with grounded theory principles and practices, prior to data collection, the participants became cognizant with the purpose and procedure of the study. Second, audio-taping was done after we sought the participants' informed consent. Third, the participants' were ensured that their real names and affiliations will not be revealed to third parties. Fourth, to make sure our conceptualization does not distort their perspectives and reflect nothing but what they presented, the emerged techniques were verified through member checking. Finally, in return for their sharing their techniques and strategies, we shared the emerged techniques with the participants.

\section{Results}

\subsection{Exposing Candidates to Sample Answers}

Participants believed that exposing candidates to sample answers improves their reading, improves their background knowledge and exposes them to common vocabulary and structure and consequently improve their writing performance in the IELTS. Supporting this technique, Mona, one of the participants explains:

One of the techniques that I use to improve learners' writing skill is using test samples. That is, I expose them to different samples. I believe they should read lots of samples because reading is the basis for writing and it helps them to write more effectively. The more they are exposed to test samples, the stronger they will get in writing.

Furthermore, encouraging candidates to read sample answers familiarizes them with mechanical aspects such as 
spelling and punctuation marks. Participants believed that conception precedes execution. That is, prior to encouraging them to apply punctuation marks or spell new words correctly, learners should be encouraged to notice these features by being exposed to samples which illustrate appropriate punctuation marks and accurate spelling. Believing that exposing candidates to sample answers improves mechanical aspects such as spelling and punctuation marks, Mina states:

I think candidates should read enough samples which aim at exposing them to punctuation marks and difficult words. For example, if I see that a candidate has spelling problems, I ask him or her to read sample answers, summarize them, and make sure the new words have not been misspelled. Not only do sample answers expose them to the correct spelling of new words, they also expose them to the correct use of words in creating message-oriented texts.

In addition to improving mechanics of writing, exposing candidate to sample answers familiarizes them with the overall structure and organization of different types of writing tasks. Believing that sample answers improve how writing tasks should be organized, Reza states:

We can't expect candidates to organize their texts correctly without first being exposed to samples of well-organized texts; hence, I encourage candidate to read sample answers and uncover their hidden structure. For instance, prior to asking them to write a compare and contrast essay, I expose them to compare and contrast sample answers.

\subsection{Teaching Vocabulary and Grammar as a Prerequisite}

Analysis revealed a bifurcation among participants concerning presenting vocabulary and grammar as a pre-requisite to writing. While some participants believed that teaching grammar and vocabulary precedes teaching writing, others believed that this is not as efficient as it looks. Those who believed in a prerequisite knowledge of grammar and vocabulary believed that writing is reasoning through the rails of grammar and vocabulary. Explaining the importance of developing candidates' vocabulary and grammar prior to involving them in writing tasks, Mina reasons:

Writing depends on knowledge of language and background knowledge of the topic at hand. Suppose, the candidate has the needed background knowledge related to the topic. Expressing his or her knowledge in writing depends on knowing related words and pertinent grammar; hence, developing learners' vocabulary and grammar prior to involving them in actual writing, enables them to express their lines of thoughts smoothly and accurately. If they do not have the prerequisite knowledge of grammar and vocabulary, their forced output will nothing like English.

Although teaching grammar and vocabulary was discovered to be important for most of the participants, there were others who believed that teaching grammar and vocabulary is inappropriate in IELTS preparatory courses due to lack of time. Instead of teaching grammar and vocabulary as a prerequisite, they believed that knowledge of language can be improved in the process of writing through corrective feedback. That is, participants believed that the writing course should involve candidates in writing tasks and improve their language by correcting their lexical and grammatical mistake. Advocating this strategy Akbar explains:

Although teaching grammar and vocabulary is necessary, it is not feasible since in IELTS preparatory courses we are pressed for time. We can raise candidates' knowledge of grammar and vocabulary through clear corrective feedback, i.e., by correcting their essays regularly, returning them to the candidates, and encouraging them to rewrite their essays by applying our corrections.

Others reject teaching grammar and vocabulary by reasoning that writing is not about knowing words and grammar; rather, it is about using words and grammar to create information-and-language-rich texts. Due to the nature of language education in EFL contexts, a great majority of IELTS candidates enjoy a large vocabulary size and have a deep knowledge of grammar but they are not able to use them in text and talk; therefore, instead of teaching them more words and grammar, in IELTS preparatory courses teachers should create conditions that are conducive to using what they have already learned. In support of this perspective, Ali reiterates:

In my classes I don't teach grammar and vocabulary since the candidates who take IELTS writing courses have already developed their vocabulary through formal education such as language education in high schools and general English and ESP undergraduate courses. Thus, rather than teaching grammar and vocabulary once again, I involve them in writing tasks that help them use the words and grammar they already know and improve their knowledge of grammar and vocabulary only indirectly through correcting their lexical and grammatical errors.

\subsection{Teaching Fixed Phrases}


Just as in teaching grammar and vocabulary as a prerequisite for writing, participants did not agree on teaching prefabricated patterns. While some of the participants advocated teaching them by arguing that knowledge of fixed phrases enhances the quality of candidates' writing, others rejected them on the grounds that indications of memorized sentences and phrases are counted against the candidates. Mona, one of the advocates of teaching prefabricated patterns argues:

One can find evident instances of prefabricated patterns in both general training and academic IELTS. Raising candidates' awareness of these phrases has a significant effect on candidates' writing performance. For example, I systematically expose them to fixed phrases in letters of complaints and then encourage them to use the phrases they learned in their subsequent tasks.

Advocates of prefabricated patters argue that using fixed phrases frees the candidates' attention away from formal analysis towards information processing. This is quite effective since the main point of writing is presenting substantial evidence is support of the thesis statement rather than showing your mastery over grammar and vocabulary. Supporting this point, Ali argues:

Fluent text and talk is possible because, I believe, authentic language use is message-oriented. That is, communication aims at getting messages across; hence, interlocutors pay conscious attention to meaning and pertinent language forms are processed subconsciously. This is possible because through exposure and repeated use, we have memorized tons of fixed phrases and while communicating we do nothing but putting memorized phrases together automatically.

Despite inherent merits of having a subconscious knowledge of fixed phrases in fluent text and talk, some participants warned against teaching them since, as Taha, explains:

Using these clichéd phrases is one of the red lines of IELTS. Unfortunately, some IELTS teachers do not heed this. You know, three groups of examinees receive a zero score: those who are absent; those who turn in a white paper; and those who write based on memorization. Teaching prefabricated patterns may lead to overuse fixed phrases. This may be taken by scorers as indicative of memorization and may be counted against the candidates

\subsection{Raising Candidates' Awareness of Scoring Criteria}

Examiners judge candidates' writing performance in IELTS in terms of task response, coherence and cohesion, grammatical version and accuracy, and lexical resource. Participants believed that raising candidates' awareness of these scoring criteria significantly improves their writing performance. Advocating this technique Mona, explains:

As an inseparable part of my teaching, I make sure that candidates deeply understand band descriptor guidelines. Using the guidelines, I explain what band scores 6, 7, and 8 entail. I also explain what scoring criteria such as task response, coherence and cohesion, grammatical version and accuracy, and lexical resource mean. For instance, I explain that task response means you should answer the question completely and avoid irrelevant information.

While some participants explicitly explained the scoring criteria, others tried to follow an inductive approach. That is, they preferred to present candidates with two different sample answers and then encouraged candidates to analyze them to uncover why one scored low while the other scored high. Advocating this approach, Mani states:

I believe candidates should be aware of scoring criteria. Instead of explaining scoring criteria, however, I present the candidates with samples that got different band scores, i.e., a sample answer that got 8 and one that got 7 . One of the possible techniques in my classes is comparing two samples of writing that e.g. one of them had received 8 and the other one 7 . I then encourage them to analyze the sample answers and explain why one scored higher than the other.

\subsection{Teaching Discourse Markers}

Writing grammatically correct sentences is quite different from writing coherent and cohesive texts. In an essay, sentences of a paragraph and paragraphs should be well-connected and this will not happen unless candidates are well aware of discourse markers and actually use them to develop their ideas. Participants believed that one cannot expect candidates to write a compare and contrast paragraph without first raising candidates' awareness of discourse markers such as 'while', 'on the other hand', 'conversely', and 'on the contrary'. Amir explains how he approaches discourse markers as follows:

To make sure that candidates can write compare and contrast paragraphs, for instance, I write pairs of sentences on the board and then have the candidate connect separate sentences. For instance, take these two sentences: (1) 
Tehran is a polluted city; (2) London is a polluted city. Using connectors such as 'similarly' and 'likewise' candidates can connect their ideas and create well-connected sentences.

While Amir makes candidates use discourse markers to achieve cohesive and coherent texts, Tina believe that teachers should help learners recognize connectors by exposing them to well-connected paragraphs and essays. Explaining the importance of making students cognizient with discourse markers prior to producing them, Tina explains:

I believe perception precedes production; hence, I raise learners' awareness of the functions of discourse markers by showing them well-connected texts such as newspaper extracts or sample answers and have learners underline or highlight the connectors and then explain why the writer used the discourse marker.

Still other participants believed that learners' awareness and use of discourse markers can be raised through discourse level corrective feedback. They believed that error correction shouldn't be limited to typographical mistakes and grammatically ill-formed sentences. It should go beyond sentences by focusing on whether candidates can develop their ideas through the use of appropriate discourse markers or not. Raising learners' awareness of discourse markers through corrective feedback, Reza explains:

I believe success in writing is contingent upon knowing grammar and having a deep knowledge of discourse markers. Therefore, in correcting candidates' sample texts, sometimes I focus exclusively on grammar and sometimes on discourse markers. That is, sometimes, I deliberately ignore their grammatical mistakes and focus on the correct use of discourse markers because many candidates have a conscious awareness of grammar but when it comes to discourse markers they either do not use them or use them haphazardly.

\subsection{Raising Candidates Content Knowledge}

Writing deficiency is rooted in candidates' knowledge of language including his or her knowledge of grammar, vocabulary and discourse markers. It is equally rooted in candidates' experiential knowledge or content knowledge. While language classes mainly focus on the former, i.e., developing learners' knowledge and use of language, writing is not about showing one's mastery of language; rather, it is about presenting your perspectives; hence, candidates who have a solid knowledge of language may not be able to write at all if they have not content knowledge. Thus, IELTS preparatory courses should develop candidates' content knowledge along with their language knowledge. Reiterating the importance of content knowledge Ali explains:

Suppose the writing task has the candidates explain whether teaching history should be part of the school curriculum or not. Despite their advanced command of English, writing is next to impossible for candidates who have nothing to say. I believe candidates' score in writing is a function of the topic and his knowledge of language. If the topic is strange to the learner, he cannot develop it even in his or her mother tongue let alone the target language.

Writing performance in IELTS writing tasks depends on candidates' awareness of top world issues; hence, participants believed that candidates should improve their knowledge of world issues through extensive reading for information. Explaining the importance of background knowledge in writing performance, Reza explains:

Taking sides and presenting substantiating evidence in support of your position depends on your language proficiency and background knowledge. For instance, to decide whether people should buy genetically modified food or not presupposes your knowledge of the inherent perils of using genetically modified food. Thus, in addition to developing your language proficiency, you should also improve your general background knowledge through reading for information.

\section{Discussion and Conclusion}

Abstraction and conceptualization of teachers' perspectives on teaching writing in IELTS preparatory course uncovered a set of strategies that seasoned teachers use to prepare IELTS candidates for writing tasks. Some of the emerged techniques have withstood the test of time because their contribution to improving performance in IELTS writing tasks have been tested under controlled conditions. For instance, in line with the previous studies (e.g., Ambe, 2008; Bagheri \& Zare, 2009), participants of this study believed that exposing IELTS candidates to sample answers significantly improves their performance in both task 1 and task 2 . Teaching prefabricated patterns was another point of convergence with the previous studies but previous studies examined its usefulness in general classes rather than in IELTS preparatory courses (e.g., Ghonsooly-Hazare, Khaghaninezhad, \& Shahriari-Ahmadi, 2010; Heidarnezhadian, Aliakbari, \& Mashhadi, 2015; Li, 2014). Furthermore, participants reiterated the importance of teaching discourse markers as an effective intervention which is in line with previous findings (e.g., Ahmadi-Fatalaki \& Nazari, 2015; Serajfard \& Allami, 2012; Patriana, Rachmajanti, \& Mukminatien, 2016). Finally, in alignment with the previous findings, the participants of this study believed in 
teaching grammar and vocabulary as a prerequisite to writing in harmony with previous studies (e.g., Decarrico, 2001; Frodesen, 2001; Fu, 2009; Rajabi \& Dezhkam, 2014).

In addition to verifying the previous findings and consequently shedding more light on techniques and strategies of teaching wiring in IELTS preparatory courses, analysis of teachers' perspectives gave rise to some techniques and strategies that have not been explored by the previous studies. As an effective intervention, participants believed that elaborating and exemplifying the scoring criteria greatly improves test-takers performance in IELTS writing tasks. Another contribution of this study to teaching writing to IELTS candidates was the awareness that encouraging learners to improve their content knowledge is an important predictor of their success in IELTs writing tasks. But in drastic contrast with the previous studies which contributed by testing effective writing interventions under experimental conditions, this study contributed by uncovering down-to-earth techniques implicit in the practice of seasoned writing teachers by abstracting and conceptualizing their perspectives on teaching writing to IELTS candidates.

To conclude, while the previous studies present IELTS writing teachers with effective interventions tested under controlled experimental conditions, this study presents practitioners with down-to-earth techniques grounded in experienced language teachers' perspectives on teaching writing to IELTS candidates. Despite their potential in improving practice, however, it is suggested that teachers and interested researchers test the effect of these propositions which are equivalent to hypotheses in quantitative studies, under controlled experimental conditions rather than take the truth-value of these data-driven techniques for granted and use them as a recipe for practice.

\section{References}

Abuseileek, A.F. (2006). The use of word processor for teaching writing to EFL learners in king Saud University. J. King Saud Univ., 19(2), 1-15.

Ahmadi, A., \& Mansoordehghan, S. (2014). Task type and prompt effect on test performance: A focus on IELTS academic writing tasks. The Journal of Teaching Language Skills (JTLS), 6(3), 1-20.

Ahmadi-Fatalaki, J., \& Nazari, M. R. (2015). The study of metadiscourse markers in academic IELTS preparation courses. Imperial Journal of Interdisciplinary Research (IJIR), 1(5), 11-16.

Ajideh, P., Leitner, G., \& Yazdi-Amirkhiz, S. Y. (2016). The influence of collaboration on individual writing quality: The case of Iranian vs. Malaysian College Students. Journal English Language Teaching and Learning Tabriz University, 17, 1-24.

Ambe, M. (2008). Exploring the role of model essays in the IELTS writing test: A feedback tool. Unpublished MA thesis, The University of Queensland, Brisbane, Queensland.

Armstrong, K., \& Retterer, O. (2008). Blogging as L2 writing: A case study. AACE Journal, 16(3), 233-251.

Bagheri, M. S., \& Zare, M. (2009). The role of using IELTS model essays in improving learners' writing and their awareness of writing features. JELS, $1(1), 115-130$.

Bozorgian, H. (2015). The relationship between listening and other language skills in international English language testing system. Theory and Practice in Language Studies, 2(4), 657-663.

Dehghan, N., \& Nosratzadeh, H. (2015). The effect of using drama on Iranian EFL learners' task response/achievement and cohesion and coherence in the IELTS. International Journal of Language and Applied Linguistics, 1(4), 26-30.

Decarrico, J. S. (2001). Vocabulary learning and teaching. In M. Celce-Murcia (Ed.), Teaching English as a second or foreign language (3rd ed.) (pp. 207-217). Boston, MA: Heinle and Heinle.

Elola, I., \& Oskoz, A. (2010). Collaborative writing: Fostering foreign language and writing conventions development. Language Learning \& Technology, 14(3), 51-71.

Frodesen, J. (2001). Grammar in writing. In M. Celce-Murcia (Ed.), Teaching English as a second or foreign language (3rd ed.) (pp. 233-248). Boston, MA: Heinle and Heinle.

$\mathrm{Fu}$, D. (2009). Writing between languages: How English language learners make the transition to fluency, grades 4-12. Heinemann, NH: Portsmouth.

Ganji, M. (2009). Teacher-correction, peer-correction and self-correction: Their impacts on Iranian students' IELTS essay writing performance. The journal of Asia TEFL, 6(1), 117-139.

Ghonsooly-Hazare, B., Khaghaninezhad, M. S., \& Shahriari-Ahmadi, H. (2010). Formulaic writing: A novel approach to writing. Pazhuhesh-e Zabanha-ye Khareji, 56, 127-148. 
Heidarnezhadian, Q., Aliakbari, M., \& Mashhadi, J. (2015). The potential impact of using prefabricated patterns (collocation expressions) on improving writing proficiency among Iranian intermediate EFL learners. International Research Journal of Applied and Basic Sciences, 9(3), 328-334.

Ketabi, S., \& Torabi, R. (2013). Teaching academic writing in Iranian EFL classrooms: Teacher-initiated comments or peer-provided feedback? Iranian Journal of Research in English Language Teaching, 1(2), 99-109.

Lan, N. T. (2015). The effect of task type on accuracy and complexity in IELTS academic writing. Tp chi Khoa hc HQGHN: Nghiên cu Nc i, 31(1), 45-63.

Li, Q. (2014). An empirical study on the application of lexical chunk to college English writing. Journal of Language Teaching and Research, 5(3), 682-688. https://doi.org/10.4304/jltr.5.3.682-688

Lin, M. H., Groom, N., \& Lin, C. Y. (2013). Blog-assisted learning in the ESL writing classroom: A phenomenological analysis. Educational Technology \& Society, 16(3), 130-139.

Ocriciano, M. (2016). IELTS writing: A gamification journey. Cambridge English: Research Notes, 64, 31-38.

O'Loughlin, K., \& Wigglesworth G. (2003). Task design in IELTS academic writing task 1: The effect of quantity and manner of presentation of information on candidate writing. International English Language Testing System (IELTS) Research Reports, 4, 88-130.

Ostovar-Namaghi, S. A. (2009). A data-driven conceptualization of language teacher identity in the context of public high schools in Iran. Teacher Education Quarterly, 36(2), 111-124.

Patriana, A. W., Rachmajanti, S., \& Mukminatien, N. (2016). Students' ability in using discourse markers to build coherence in compositions. TEFLIN Journal, 27(2), 203-216.

Paulus, T. M. (1999). The effect of peer and teacher's feedback on student' writing. Journal of Second Language Writing, 8(3), 265-289. https://doi.org/10.1016/S1060-3743(99)80117-9

Rajabi, P., \& Dezhkam, E. (2014). The effect of explicit grammar instruction on improving writing accuracy of Iranian EFL learners. Journal of ELT and Applied Linguistics, 2(1), 61-76.

Sanonguthai, S. (2011). Teaching IELTS writing module through English debate: A case study in Thailand. Language Testing in Asia, 1(4), 39-99. https://doi.org/10.1186/2229-0443-1-4-39

Serajfard, H., \& Allami, H. (2012). Engagement markers: A technique for improving writing skills. Journal of Language, Culture, and Translation (LCT), 1(1), 71-83.

Storch, N. (2005). Collaborative writing: Product, process, and students' reflections. Journal of Second Language Writing, 14, 153-173. https://doi.org/10.1016/j.jslw.2005.05.002

Vahdani-Sanavi, R., \& Nemati, M. (2014). The effect of six different corrective feedback strategies on Iranian on Iranian English language learners' IELTS writing TASK 2. Sage Open, 4(2) 1-9.

Van- Leeuwen, C. A., \& Gabriel, M. A. (2007). Beginning to write with word processing: Integrating writing process and technology in a primary classroom. The Reading Teacher, 60(5), 420-429. https://doi.org/10.1598/RT.60.5.2

Vurdien, R. (2012). Enhancing writing skills through blogs in an EFL class. The EUROCALL Review, 20, $155-158$.

\section{Copyrights}

Copyright for this article is retained by the author(s), with first publication rights granted to the journal.

This is an open-access article distributed under the terms and conditions of the Creative Commons Attribution license (http://creativecommons.org/licenses/by/4.0/). 